\title{
A Expansão Urbana, o Mercado Imobiliário e a Proliferação dos Enclaves Residências Horizontais no bairro Colônia do Marçal, em São João del-Rei (MG)
}

\author{
Urban Sprawl, Real Estate Market and the Proliferation of Horizontal Residential \\ Enclaves in the Neighborhood Colônia do Marçal, in São João del-Rei (MG)
}

La Expansión Urbana, el Mercado Inmobiliario y la Proliferación de los Enclaves Residenciales Horizontales en el Barrio Colonia del Marçal, en San Juan del Rey (MG)

\author{
Jeziel Silveira Silva ${ }^{1}$ \\ Marcio Roberto Toledo ${ }^{2}$
}

\begin{abstract}
RESUMO: A partir de meados dos anos 2000, vem aumentando o número de condomínios horizontais fechados na paisagem urbana, tanto nas grandes quanto nas pequenas cidades. Este artigo analisa o surgimento e consolidação de enclaves fechados, no município de São João del-Rei (MG), através da análise de sua proliferação no sentido norte-nordeste da cidade, no bairro Colônia do Marçal. Além disso, como objetivos específicos, analisa a atuação dos agentes envolvidos, como os donos de terras ou incorporadores do setor imobiliário para a propagação deste modelo de habitação, além de fatores como medo, violência e natureza, que são as principais causas da busca por estes enclaves, principalmente pela classe média e alta. Para a execução da pesquisa, foram realizados levantamentos bibliográficos e aplicados questionários para a população residente nesse tipo de habitação, o que permitiu avaliar questões econômicas e de caráter social, que visavam caracterizar e identificar as causas da busca por esse tipo de moradia, a relação entre sua expansão e a ação dos agentes envolvidos, assim como as consequências acarretadas por esse modo de habitar na cidade.
\end{abstract}

PALAVRAS-CHAVE: Condomínios habitacionais fechados. Expansão urbana. Agente imobiliário.

ABSTRACT: Since the mid-2000s the number of horizontal condominiums in the urban landscape has increased, both in large and small cities. This article analyzes the emergence and consolidation of closed enclaves, in the city of São João del-Rei (MG-Brazil), through the analysis of its proliferation in the north-northeast direction of the city, in the neighborhood Colônia do Marçal. In addition, as specific objectives, we will analyze the performance of the agents involved, such as landowners or real estate developers for the propagation of this housing model, in addition to factors such as fear, violence and nature, which are the main causes of the search for these enclaves, mainly by the middle and upper

\footnotetext{
${ }^{1}$ Universidade Federal de São João Del Rei - UFSJ. Avenida Visconde do Rio Preto, s/n - Colônia do Bengo, MG, 36301-360. jezielsilveira@hotmail.com.

${ }^{2}$ Universidade Federal de São João Del Rei - UFSJ. Avenida Visconde do Rio Preto, s/n - Colônia do Bengo, MG, 36301-360. mtoledo@ufsj.edu.br.
} 
A Expansão Urbana, o Mercado Imobiliário e a Proliferação dos Enclaves Residências Horizontais no...

classes. In order to carry out the research, bibliographical surveys and questionnaires were carried out for the population living in this type of housing, which allowed the evaluation of economic and social issues that aimed to characterize and identify the causes of the search for this type of housing, the relationship between its expansion and the action of the agents involved, as well as the consequences of this way of inhabiting the city.

KEYWORDS: Housing condos closed. Urban expansion. Real estate agents.

RESUMEN: A partir de mediados de los años 2000 viene aumentando el número de condominios horizontales cerrados en el paisaje urbano, tanto en las grandes como en las pequeñas ciudades. Este artículo analiza el surgimiento y consolidación enclaves cerrados, en el municipio de São João Del Rei (MG-Brasil), a través del análisis de su proliferación en el sentido norte-noreste de la ciudad, en el barrio Colonia do Marçal. Además, como objetivos específicos, analizaremos la actuación de los agentes involucrados, como los dueños de tierras o incorporadores del sector inmobiliario para la propagación de este modelo de vivienda, además de factores como miedo, violencia y naturaleza, que son las principales causas de la búsqueda por estos enclaves, principalmente por la clase media y alta. Para la ejecución de la investigación, se realizaron encuestas bibliográficas y aplicados cuestionarios para la población residente en este tipo de vivienda, el que permitió evaluar cuestiones económicas y de carácter social, que pretendían caracterizar e identificar las causas de la búsqueda por este tipo de vivienda, la relación entre su expansión y la acción de los agentes involucrados, así como las consecuencias acarreadas por este modo de habitar en la ciudad.

PALABRAS-CLAVE: Condominios habitacionales cerrados. Expansión urbana. Agente inmobiliario.

\section{INTRODUÇÃO}

Nos anos 2000, a força do processo de globalização acentuou as alterações no espaço urbano, principalmente na perspectiva de habitação, desencadeando maior segregação espacial, visto que as cidades começaram a aglomerar um número colossal de habitantes. Hoje, por meio do mercado imobiliário, ocorre uma deficiência artificial de lotes ou moradias urbanas (DUMONT, 2014).

O aproveitamento do solo urbano se individualiza de uma cidade para outra, mas, de modo geral, podemos esquadrinhar algumas similaridades, como a instalação de zonas de residências, com a presença dos loteamentos fechados e condomínios horizontais. Esses fenômenos levantam diversas questões que se tornam relevantes para averiguar as profundas mudanças no desenvolvimento urbano e, por conseguinte, nas cidades (DAL POZZO, 2011).

O espaço urbano é um reflexo tanto de ações que se realizam no presente, como daquelas que se realizaram no passado, tornando-se capazes de permanecerem presentes nas atuais fisionomias espaciais (CORRÊA, 1989). As alterações no espaço urbano em São João del-Rei nas últimas décadas são motivadas por múltiplos fatores socioeconômicos. 
O centro da cidade de São João del-Rei vem deixando de ser uma localidade para residências, mas permanece mantendo sua importância, essencialmente como local comercial e de serviços (ESTEVES; NOGUEIRA, 2013). Atualmente, ocorre uma expansão da malha urbana em direção às áreas periféricas da cidade, em particular ao bairro Colônia do Marçal, que, a partir dos anos 2000, apresenta uma forte especulação imobiliária, demonstrada pela inauguração de diversos empreendimentos, como loteamentos e condomínios horizontais fechados, além do aumento significativo no número de imóveis construídos (ANDRADE et al., 2014).

Porém, este sistema de parcelamento de solos em bairros periféricos, conforme Jordão (2010) favoreceu a dilatação horizontal demasiada, consoante ao gerenciamento da prática do mercado fundiário especulativo e dos loteadores. Logo, a propriedade fundiária da periferia urbana transfigura-se em objeto para os proprietários de terra. Tal circunstância se dá devido à passagem do espaço rural para o urbano, onde subsequentemente o uso da periferia agrícola é substituído pelo urbano, levando à esterilização da terra e à valorização fundiária.

Ora, o desdobramento de formas de incorporação entre o capital financeiro e o setor imobiliário fortifica e aprimora o domínio da ação do grande capital em relação ao urbano, uma vez que os empreendimentos influenciados pela sua racionalidade se localizam no prestigiado vetor de enaltecimento, apreciação e valorização imobiliária da cidade, sendo apto de impulsionar o surgimento de novos eixos de valorização em zonas afastadas dos centros tradicionais (BOTELHO, 2007). Assim, os proprietários de terra atuam com 0 propósito de obterem uma renda fundiária maior através de suas propriedades, pois estão interessados na transmutação da terra rural em terra urbana, já que a cidade tende a se expandir através do meio urbano, estimulando, assim, uma maior valorização, ou seja, o interesse se torna mais favorável perante o valor de troca da terra e não o seu valor de uso (CORRÊA, 1989).

Desse modo, as modificações sofridas no espaço urbano de São João del-Rei, no que diz respeito à habitação, têm proporcionado novas práticas sócio-espaciais e novas formas de diferenciação no uso do solo. Conforme Corrêa (1989), a segregação residencial é, em veracidade, um desenvolvimento que estimula a predisposição e sistematização espacial em áreas de intensa homogeneidade social interior e disparidade entre elas.

Desta forma, o objetivo deste trabalho foi analisar o surgimento e consolidação de enclaves fechados, no município de São João del-Rei (MG), através da apreciação de sua proliferação no sentido norte-nordeste da cidade, no bairro Colônia do Marçal. As hipóteses são as de que (1) os enclaves fortificados horizontais vêm criando novos modelos de habitação nas cidades, acarretando desigualdades socioespaciais; (2) a atuação dos agentes envolvidos neste cenário de expansão dos enclaves (donos de terras ou 
incorporadores do setor imobiliário) é fundamental para a propagação deste arquétipo de habitação; e (3) o medo da violência e da criminalidade agregados com o "status" de morar perto da natureza são as principais causas da busca pelos enclaves horizontais, principalmente pela classe média e alta. Foram aplicados questionários para residentes em enclaves horizontais, a fim de caracterizar e identificar as causas da busca por este tipo de moradia. A luz das leituras e teorias levantadas, analisamos a relação entre sua expansão e a ação dos agentes envolvidos, assim como as consequências dos enclaves para a segregação socioespacial no município.

Por fim, nessas zonas, começam a surgir singularidades, acompanhadas de soluções habitacionais, as quais são destinadas às camadas médias e ricas, pactuando na convicção de megaprojetos imobiliários, originando e organizando novas centralidades que exibem o espaço urbano das cidades (PEREIRA, 2005).

\section{A CIDADE DE SÃO JOÃO DEL REI E SUA EXPANSÃO URBANA}

De acordo com o Instituto Brasileiro de Geografia e Estatística (IBGE), a cidade de São João del-Rei localizada na Mesorregião do Campo das Vertentes (Figura 1), sudoeste do estado de Minas Gerais, apresenta uma população estimada de 90.263 habitantes (IBGE, 2018), compreendida em 8 grandes bairros: Bonfim, Centro, Colônia do Marçal, Fábricas, Jardim Central, Matosinhos, Senhor dos Montes e Tijuco, apresentando 95\% da sua população residente na zona urbana (OLIVEIRA; TOLEDO, 2016).

Figura 1- Localização da cidade de São João del-Rei (MG)

\section{LOCALIZAÇÃO DO MUNICIPIO DE SÃO JOĀO DEL-REI}

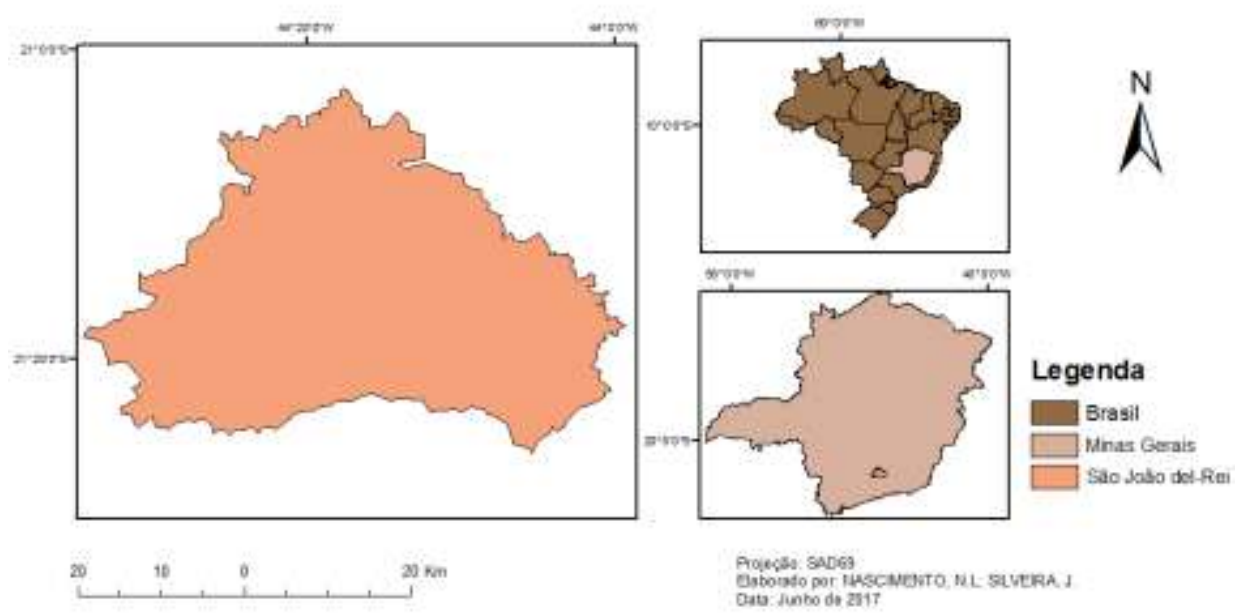

Fonte: Silva (2017). 
A assimilação do uso destoado do solo urbano junto às modificações econômicas do processo capitalista, tais como "[...] a internacionalização, transnacionalização e globalização [...]" (GOMES; AGUIAR, 2012, p. 40), são generalidades basilares para reconhecimento da formação e estruturação territorial que, em contrapartida, pode ser explicada pelo processo de aceleração sem pretextos da expansão urbano-industrial, que se destacou ao longo do século $\mathrm{XX}$, acarretando de forma fracionada na participação da população urbana nas áreas centrais (BLATT; TOMÁS; MACHADO, 2010), como o caso de São João del-Rei.

A formação urbana de São João del-Rei teve início no século XVIII, transversalmente estabelecida através das relações de interesse dos comerciantes e dos agentes que detinham o controle administrativo do local, além do exercício de atividades, principalmente da extração de ouro que se localizava nas encostas. Mais tarde, no século XIX, novos elementos, como a Companhia Industrial São Joanense e a Ferrovia Oeste de Minas, que se tornaram primordiais para o crescimento demográfico e a expansão urbana (MALDOS, 2000).

Em consequência do processo de crescimento e urbanização acelerada, na década de 1970 amplificou-se singularmente o processo de formação das áreas periféricas urbanizadas, dado o exposto de que o município: "Na qualidade de cidade-pólo de uma mesorregião economicamente deprimida, passa a atrair, contingentes de emigrantes da zona rural e da área urbana de pequenos municípios próximos, ensejando a constituição e contínua ampliação de novas periferias" (CARNEIRO, 2009, p. 5).

Segundo Corrêa (1989), ocorre diferenciações na forma de ocupação urbana em relação ao uso residencial em periferias, sendo elas: urbanização de status e urbanização popular. Nesse horizonte, as estratégias dos proprietários fundiários variarão de acordo com o domínio das formas, através das quais as terras bem localizadas em áreas valorizadas por amenidades físicas, as quais Corrêa (1989) aponta como mar, lagoa, áreas verdes etc. sofrerão um aumento no preço da terra e serão destinadas à população de status.

Todavia, as transformações na paisagem e no espaço urbano do município, principalmente no século XXI, são notáveis, quando se observa que a cidade passou a ser mais segregada, além da sobreposição de interesses individuais aos interesses coletivos, considerando-se ainda os primitivos problemas de habitações, tanto na condição do processo seletivo e no acesso à terra urbana e na localização destas terras.

Logo, as metamorfoses conduzidas a partir das alterações do capitalismo contemporâneo, em suas numerosas e, cada vez, mais, heterogêneas escalas de efetuação, têm motivado alternâncias nos fluxos demográficos e demandas por novos espaços (BATELLA, 2014, p. 240) nas cidades médias, "[...] que se baseiam exclusivamente em critérios de tamanho demográfico, como a elaborada pelo IPEA, IBGE, UNICAMP (2001) 
A Expansão Urbana, o Mercado Imobiliário e a Proliferação dos Enclaves Residências Horizontais no...

são utilizadas no reconhecimento das cidades de porte médio que, no caso brasileiro, são aquelas que possuem entre 50 mil e 500 mil habitantes".

Entretanto, com o impulso da industrialização, esse conjunto de cidades passou (e vem passando) por transfigurações imediatas, e dadas seu ofício central na composição do método capitalista de produção, foi sem hesitações o substancial transmissor da redefinição da ordem de urbanização (MOTTER; BATELLA, 2015). A produção do espaço urbano em cidades médias vem se estabelecendo através de elementos que norteiam práticas socioespaciais, seguindo interesses especulativos da produção imobiliária junto à potencialidade de expansão pela área urbana. Logo, acarretam novos traços e formas de habitat urbano, como por exemplo, os condomínios horizontais fechados (ZANDONADI, 2005).

Sendo assim, tais avanços no processo de urbanização da cidade acabam agindo sucessivamente, influenciando o aproveitamento dos espaços pelos cidadãos (MARINHO, 2017). Dessa forma, as propagações de condomínios fechados, que, preliminarmente, se limitavam às metrópoles, agora estabelecem a popularização pelas cidades médias (ESTEVES; NOGUEIRA, 2013).

\section{A EXPANSÃO DO BAIRRO COLÔNIA DO MARÇAL E A ESPECULAÇÃO IMOBILIÁRIA}

O bairro Colônia do Marçal, ocupado no século XIX pelos imigrantes italianos que praticavam atividades agrícolas, serviços gerais e cultivo de hortaliças (TEIXEIRA, 2011) localiza-se aproximadamente a cinco quilômetros do centro da cidade de São João del-Rei, limitando-se com duas cidades vizinhas em suas bordas: Santa Cruz de Minas e Tiradentes. Existem no bairro duas importantes avenidas: a principal Avenida 31 de Março (BR 383), caracterizada como uma das maiores da cidade, onde se localiza uma colossal rede de empreendimentos (hotéis, postos de gasolina, restaurantes, padaria, farmácias, bares, academias), além de uma variedade de comércios e a outra, denominada Avenida Luís Giarola, com caráter mais residencial (habitações durante o trajeto), e de poucos estabelecimentos comerciais (Figura 2).

Uma apreciação histórica do bairro mostra que, "[...] os imigrantes ali instalados foram incorporados à sociedade local com o status de empresários ou empreendedores, atuando tanto no setor industrial (tecelagem) quanto no comercial e de serviços, incluindo aí as empresas de construção civil" (SILVA, 2018, p. 78).

Teixeira (2011) remete a um fato importante sobre os italianos e o Estado naquela época. Muitos imigrantes, ao receberem lotes do Estado, os destinaram a terceiros, não desfrutando do terreno ou o aproveitando para construção de casas, para firmarem residência. Nessa circunstância, os proprietários fundiários começam a se tornar promotores 
imobiliários, os quais loteiam, vendem e constroem casas de luxos nessas áreas (CORRÊA, 1989).

Figura 2 - Vetor de Expansão da cidade de São João Del Rei (2000-2018)

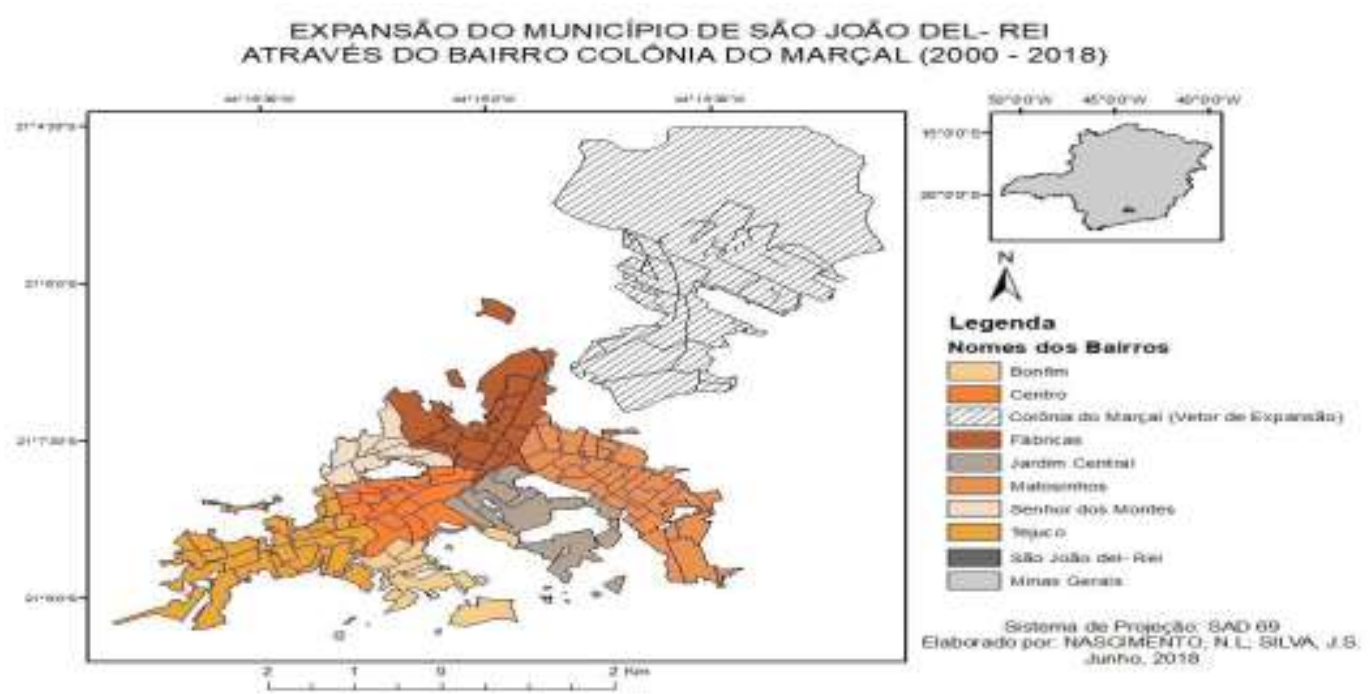

Fonte: Silva (2018).

De acordo com Corrêa (1989), a procura de terras e habitações vem da presença de novas classes sociais, descendentes em parte de fluxos migratórios e que dispõem de renda que as transfiguram aptas a participarem do mercado de terras e habitações.

Assim sendo, grande parte dos imigrantes acabaram vendendo os terrenos recebidos ou fracionando-os de acordo com as suas necessidades, fazendo com que alguns lotes ficassem maiores ou menores. Em decorrência da divisão e das vendas empreendidas pelos próprios colonos, o bairro tornou-se vulnerável às mudanças, sem influência direta do Estado, auxiliando, dessa maneira, pelas famílias proprietárias de terra na região, modificações em suas propriedades rurais, tornando-as loteamentos urbanos (UEDA, 2005).

Outro aspecto que merece ser destacado, de acordo com Teixeira (2011), é a nova configuração social do próprio bairro Colônia, que se transformou com essa desagregação e vendas, sobre as quais Ueda (2005) afirma relacionarem-se com a eflorescência de novos sujeitos, variáveis de valorizações e práxis produtivas no território, viabilizando refletir sobre a ação, influência e dinâmica do setor imobiliário na produção dos municípios.

A recapitulação da história da imigração italiana no bairro Colônia do Marçal é importante para a compreensão do uso e ocupação do solo em São João del-Rei, principalmente nos séculos XX e XXI. Com o crescimento da população urbana superior à população rural, as cidades aumentaram de tamanho sem a infraestrutura adequada, acarretando em uma má disseminação dos indivíduos, o que desencadeou a eclosão de imensuráveis distúrbios e mudanças nos aspectos sociais (GARROTE; MEDA, 2017). 
A Expansão Urbana, o Mercado Imobiliário e a Proliferação dos Enclaves Residências Horizontais no...

Todavia, os domínios econômicos, como a indústria, a agricultura e o comércio reestruturaram-se, reorganizando o bairro. O aperfeiçoamento desses setores foi apoiado pelo alto crescimento demográfico da urbanização são-joanense (GOMES; AGUIAR, 2012). Em decorrência desse processo, a partir dos anos 2000, o bairro começou a pluralizar aceleradamente e sem controle, em consequência de uma forte especulação imobiliária, o que contribuiu para fortalecer os processos de dispersão espacial e fragmentação.

Além da reconfiguração das relações do espaço e sua produção, surgem, ao lado da dinâmica socioespacial novas formas de agentes. Tais agentes podem ser descritos como donos de terras ou incorporadores do setor imobiliário, que, conforme apresentam Cota e Dório (2012, p. 5),

[...] despertaram para a possibilidade de agregar valor às áreas até então, não ocupadas - seja loteando áreas de expansão urbana municipal, ou parcelando glebas rurais - transformando-as em lucrativos produtos imobiliários. Esse tipo de incorporação vem atender ao segmento de média renda da população que se instala de forma acelerada na cidade, incrementando o processo de espraiamento do tecido urbano e induzindo o crescimento de áreas também periféricas, porém legais, por meio dos loteamentos urbanos.

Segundo Andrade et al. (2014), a expansão de imóveis e infraestruturas tipicamente urbanas em áreas periféricas (como condomínios fechados e loteamentos) contribui para desenvolver bairros selecionados, que deixam de ser vistos como periféricos, embora localizados na periferia urbana (CORRÊA, 1989). Entretanto, tal evento motiva os agentes imobiliários a lançarem novos empreendimentos em áreas mais afastadas, anteriormente habitados por uma população predominantemente de baixa renda, ou pela atividade agropecuária, elevando os preços dessas áreas, ressaltando que Koch (2008. p. 101) salienta:

A expansão urbana realizada pelos agentes produtores do espaço urbano (mercado imobiliário e produção estatal) implica condições diferenciadas de acesso ao solo, o que propicia distintos modos de uso e ocupação desse solo, levando a diversidades sociais, refletidas tanto no modo de quanto no acesso a apropriação e uso da terra.

Maia (2017) destaca o papel do Estado e sua atuação, em virtude da sua supremacia diante da infraestrutura física e social para a reprodução social, uma vez que, as deliberações de recursos pelo Estado concernem diretamente ao setor imobiliário, fomentando atos especulativos nos incorporadores e proprietários fundiários. Assim sendo, o setor imobiliário e seus múltiplos agentes são capazes de promover um processo de segregação sócio espacial, uma vez que nem todo cidadão tem acesso à moradia em boas 
condições, conforme Dumont (2014, p. 135), posto que: "A valorização extremamente desigual das áreas da cidade instaura a segregação espacial e a desigualdade urbanística, ou seja, nem todos os cidadãos podem fruir por todas as áreas urbanas".

Além disso, agregado aos especuladores de terras urbanas, as classes de maior poder aquisitivo (classe média e classe média alta) tecem mecanismos para isolar-se dos desprovidos e da população de baixa renda (estabelecendo uma segregação espacial, social e econômica ainda maior), uma vez que: "A elite brasileira migra à procura de melhores locais para residência, de acordo com o crescimento da cidade. Regiões centrais e suas adjacências são privilegiadas. A classe média, por sua vez, passa a habitar as zonas verticalizadas de média e alta densidade" (BERNARDES; JÚNIOR, 2007, p. 2011).

Por fim, uma nova organização espacial é formada, cercada de novas territorialidades, relações sociais e novas proporções e aplicabilidades no uso da terra, criando, estabelecendo, estimulando e intensificando o processo de segregação sócio espacial e residencial que singulariza a cidade capitalista (BARROS, 2012).

\section{NOVAS FACES DE HABITAÇÃO: A PROLIFERAÇÃO DOS CONDOMINÍOS HORIZONTAIS RESIDENCIAIS NO BAIRRO COLÔNIA DO MARÇAL}

Recentemente, observa-se a privatização dos espaços de residência e o domínio dos condomínios fechados horizontais. Para os autores Caldeira (2000), Ueda (2005), e Jordão (2010) condomínios fechados podem ser tipificados como espaços que possuem caráter de lazer, moradia, consumo, trabalho, destinado às classes médias e altas, gradeados por muros ou barreiras físicas, acoplados de aparatos e equipamentos tecnológicos (câmeras, seguranças) que proliferam um relacionamento de exclusão, segregação e negação com o resto da cidade. Caldeira (1996, p. 303, tradução dos autores) caracteriza esse domínio como "enclaves fortificados", que são: "[...] espaços privatizados, fechados e monitorados para residência, consumo, lazer ou trabalho".

A expansão e a proliferação desse modelo de habitação correspondem à versão ideal do novo conceito de domicílios, inserindo em seu contexto generalidades como: afastamento da zona urbana, segurança, status, e, principalmente, contato com a natureza. Os autores Bernardes e Soares Júnior (2007, p. 212) aduzem que essas generalidades já existiam, dado ao exposto que:

No entanto, não era só uma questão de segurança, uma vez que o próprio condomínio vertical assegurava esse fato. Abria-se um mercado promissor, oferecendo além da segurança, um espaço mais homogêneo, distante da malha urbana, relativamente funcional e com muita área verde. 
A Expansão Urbana, o Mercado Imobiliário e a Proliferação dos Enclaves Residências Horizontais no...

Por outro lado, Caldeira (2000) afirma que esse tipo de habitação viabiliza cinco elementos básicos - (segurança, isolamento, homogeneidade social, equipamentos e serviços), e Ueda (2005) assegura que se torna primordial identificar quais são os elementos mais importantes desses tipos de habitação, pois eles podem diversificar em relação aos outros moldes de empreendimentos.

Ademais, os condomínios fechados se apresentam com elementos de diferenciação e distinção, definindo barreiras com os desiguais. Segundo Bernardes e Soares Júnior (2007), essas condições de ocupações são próprias de caráter segregatórios, inseridos no campo da cidade, especialmente a partir dos anos 1990, mas que já possuía evidências nas décadas de 1970 e 1980, reestruturando o modo de viver e morar. Diante disso, Koch (2008, p. 100) acentua um efeito importante desses empreendimentos: "O desenvolvimento desses empreendimentos coincide com o aprofundamento da fragmentação do espaço social, manifestando-se através de aspectos físicos de descontinuidade entre superfícies (fragmentos) e da segregação".

O bairro Colônia do Marçal hoje conta com a presença de seis enclaves horizontais fortificados (Figura 3). É preciso ressaltar que, para este estudo, foram selecionadas as estruturas habitacionais de maior porte, sendo elas: Recanto da Serra, Jardins Coloniais e o novo empreendimento, que foi ponto de partida para a criação deste trabalho, Campana Del Vento, que emergiu em 2016 no bairro de estudo.

Dentre estes, os Jardins Coloniais e o Campana Del Vento localizam-se na Avenida Luís Giarola que, como anteriormente descrita, é uma das maiores do bairro, asfaltada e ocupada por residências de alto padrão e pousadas ao seu redor. Já o condomínio Recanto da Serra se localiza em uma das entradas paralelas da Avenida Luís Giarola, sem infraestrutura (asfalto, por exemplo), cercados por residências secundárias onde, Silva (2009) caracteriza tais residências como casa de praia, casa de campo, chalé, cabana e rancho, que servem para descanso, lazer ou moradia temporária, além de terrenos vazios amontoados e fragmentados, sobre o que, Bernardes e Soares Júnior (2007, p. 219) evidenciam: "A implementação dos condomínios fechados tem atraído outros investimentos, ativando um círculo de crescimento, ainda incalculável. Houve uma valorização dos terrenos, os preços subiram".

Em análise introdutória, a nomenclatura dos enclaves (Figura 4) remete à ideia das condições ambientais, pois se localizam perto de áreas verdes pressupondo uma idealização maior de contato com a natureza, ar puro e tranquilidade, conforme menciona Bricalli (2010, p. 14), já que:

A apropriação da natureza por parte dos condomínios e loteamentos é feita, sobretudo pelas propagandas sob a forma de folders ou livretos que servem 
à promoção do imóvel. Tais propagandas buscam associar a presença ou proximidade ao empreendimento de algum elemento natural a um modo de vida distinto do associado ao ambiente urbano, onde reina a tranquilidade, que só poderá ser alcançada por quem ali adquirir um imóvel.

Figura 3 - Mapeamento dos Enclaves Residências Horizontais (2000-2018)

ENCLAVES FORTIFICADOS RESIDENCIAIS HORIZONTAIS (2000 - 2018) Bairro Colônia do Marçal- São João del-Rei
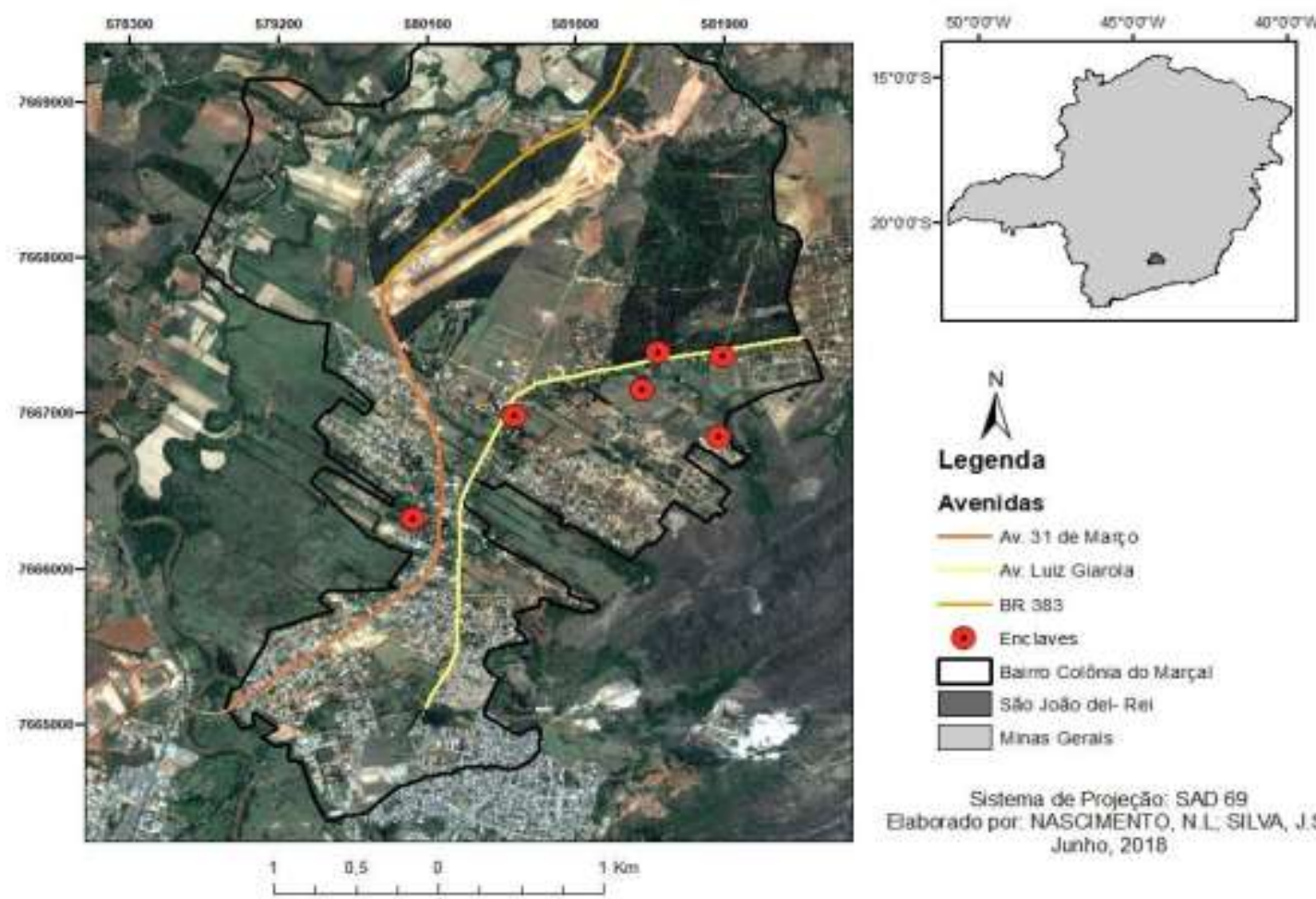

Sistema de Projeçăo: SAD 69 Eabarado por NASCMAENTO, NL. SHLVA, J.S Junho, 2018

Fonte: Silva (2018).

Tal perfil de empreendimento é apenas um item do que se assentou denominar de qualidade de vida, referida por Martins (2008, p. 16) como "[...] noção multidimensional, relativa e evolutiva, historicamente tecida, no século $X X$, entre o incremento do nível e conforto de vida", além da convicção enquanto paisagem (ANDRADE, 2005).

A finalidade da propaganda é atrair, seduzir e convencer o comprador a respeito do produto anunciado. Os anúncios, folders e encartes distribuídos usam um conjunto de concepções que discorrem a respeito da sensibilidade e da fantasia das pessoas, a fim de alcançar seus desejos, além de compartilhar estilos semelhantes de vidas, principalmente quando se direcionam tais estilos às camadas mais elitizadas. "Os anúncios não só revelam um novo código de distinção social, mas também tratam explicitamente a separação, o isolamento e a segurança como questões de status. Em outras palavras, eles repetidamente expressam a segregação social como um valor" (CALDEIRA, 1996, p. 308, tradução nossa).

Durante esta pesquisa, foram visitadas duas unidades do ramo imobiliário dentro do próprio bairro, a fim de se averiguarem alguns aspectos (Quais são os motivos que levam a 
procura de residências em condomínios fechados? Qual o perfil dos moradores dos condomínios? Ocorreu uma maior procura pelos condomínios nos últimos 10 anos?).

Figura 4 - Fachada dos Enclaves Residenciais Horizontais Fechados - Figura A: Recanto da Serra - Figura B: Jardins Coloniais - Figura C: Campana Del Vento Figura D: Village

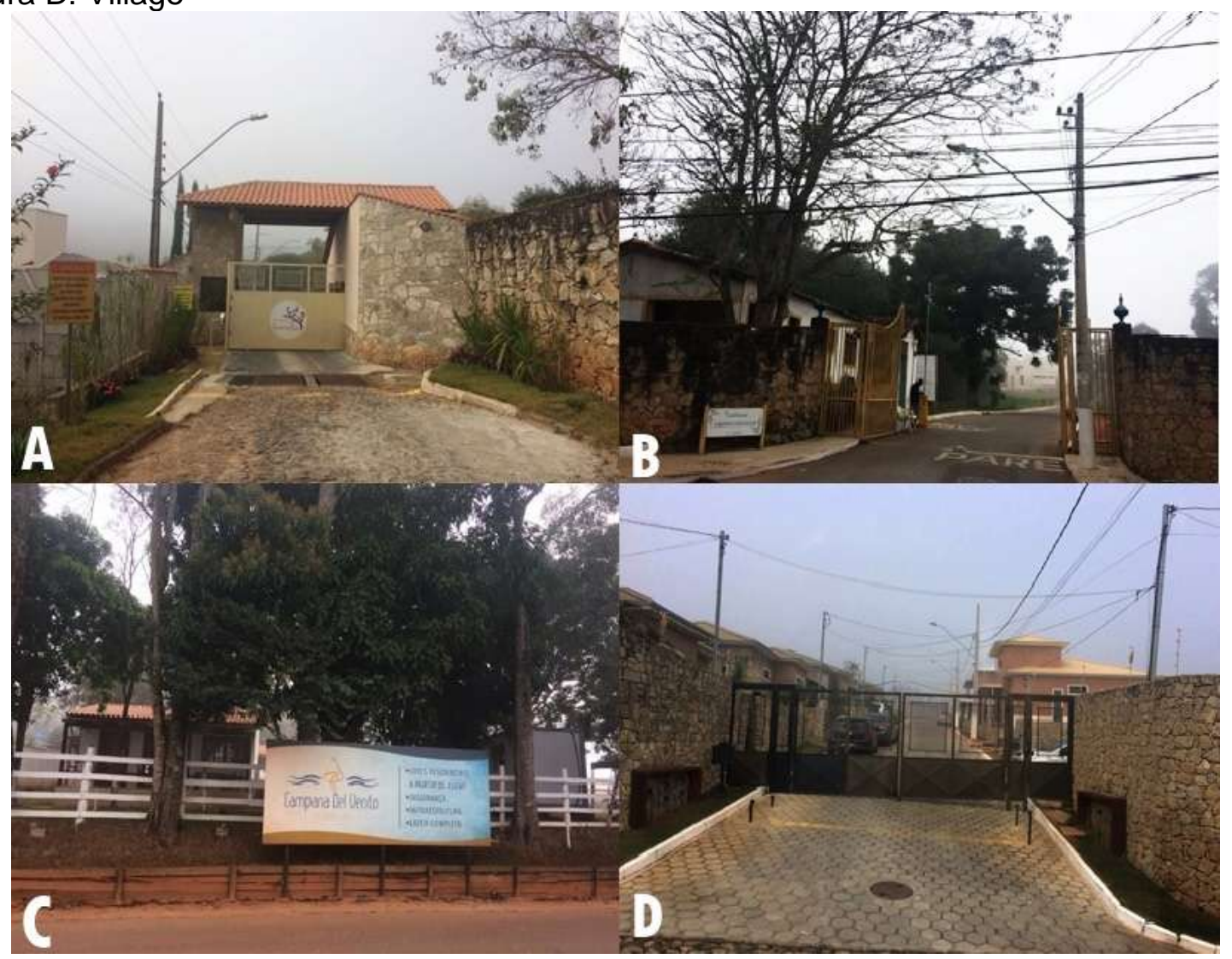

Fonte: Silva (2018).

Em análise, a primeira imobiliária visitada, com mais de 15 anos alocada no bairro, não soube falar sobre os condomínios, pois eles não trabalham com esse estilo de empreendimento, porém ressaltaram a procura de moradores residentes de outros bairros da cidade por loteamentos no entorno dos enclaves. Já a segunda imobiliária entrevistada, trabalha com os loteamentos no entorno e com a venda de lotes nos condomínios fechados, principalmente com o novo enclave, Campana Del Vento. É interessante verificar, no depoimento transcrito, como o corretor imobiliário aponta algumas características do novo enclave:

O condomínio hoje conta com uma área total de 350.000 metros quadrados com lotes a partir de 450 metros quadrados. Grande parte dos compradores é da própria cidade, residentes de outros bairros que buscam por segurança. O Campana Del Vento oferece ao comprador: controle de acesso, portaria 24 horas, circuito interno de câmeras e ronda motorizada, 
fechamento em seu entorno todo. Além disso, o morador irá desfrutar de praças, clube, trilha ecológica, nascentes e do campanário.

Os valores dos lotes residenciais variam de acordo com a zona. Temos lotes na faixa de 165 mil reais, os lotes centrais variam em torno de 180 mil reais e os localizados mais perto da Reserva Legal e da Trilha Ecológica são acima de 210 mil reais. São mais de 300 lotes onde cerca de 140 já foram vendidos.

Para mim, ocorreu uma valorização muito grande dos terrenos perto do Campana. Atualmente, se tem observado a abertura de novos loteamentos.

Um dos fatores que mais chama atenção nas entrevistas (tanto dos corretores quanto dos moradores) é a preocupação com a segurança: "[...] o conviver urbano, então, criou extensa face de medo e desigualdade social. O território fundamentado por cidades foi e permanece fronteiriço, limitador, limitado entre seres, grupos, diferenças econômicas, modos de segurança que amarram, mas não libertam" (GARROTE; MEDA, 2017, p. 193). A argumentação mais comum para a consolidação desses espaços habitacionais é justificada pelos altos índices de violência nas cidades (MOREIRA JÚNIOR, 2010). Para Caldeira (1996, p. 307, tradução nossa), "Com o crescimento da violência, da insegurança e do medo, os cidadãos adotam novas estratégias de proteção, as quais estão modificando a paisagem urbana, os padrões de residências".

Surgem assim, os novos sistemas de segurança, que se tornam estruturas fundamentais para esse atual modelo de habitação, pois: "O muro à primeira vista serve para isolar os de dentro excluindo os que têm que ficar do lado de fora. Na verdade, tem uma função latente, bem mais difícil de perceber, apesar de tão importante quanto obvia: barreira física que envolve o conjunto" (PAULO, 2017, p. 30).

A partir disso, desaponta então a razão para a estruturação de muros, guaritas, equipamentos que causam segurança (câmeras, alarmes, ronda), "[...] mas que se torna uma tendência de separação e auto segregação através do emuralhamento, tracejado na justificativa de violência" (MOREIRA JUNIOR, 2010, p. 7).

\section{AFINAL, QUEM BUSCA POR SEGURANÇA?}

As cidades se estruturaram inseridas no sistema capitalista de produção, que se manifesta por expressiva desigualdade entre as classes sociais. $O$ avanço capitalista e os incomensuráveis distúrbios urbanos relacionados à veloz industrialização intensificaram a conduta individual e a apartação espacial das classes sociais dentro da cidade: os bairros de pobres e os bairros de ricos.

Ter uma habitação individualizada escoltada de espaços era prenúncio de prestígio social, só disponível para as camadas privilegiadas (SPOSITO, 2000). Tais contrastes se concretizam dentro do espaço urbano e se convertem ainda mais perceptíveis através do 
A Expansão Urbana, o Mercado Imobiliário e a Proliferação dos Enclaves Residências Horizontais no...

déficit habitacional, como resultado da concentração fundiária no espaço urbano (MAIA, 2017).

\begin{abstract}
Obviamente o monopólio de terrenos urbanos e a sua consequente valorização têm consequências profundas para o desenvolvimento da cidade. Isto acontece porque a demanda por solo urbano nas cidades é diferenciada de acordo com o poder aquisitivo das classes sociais que a compõem. A busca das classes sociais economicamente mais privilegiadas por distinção indica a escolha de moradias localizadas nas áreas mais valorizadas da cidade, enquanto as menos privilegiadas fixam residência onde a condição econômica permitir. Neste sentido, a valorização de terrenos em função de sua localização que resultará na renda de monopólio, significará, em última instância, o uso diferenciado do espaço por ricos e pobres, acentuando a segregação espacial das cidades (BRICALLI, 2010, p. 104).
\end{abstract}

Grande parcela dos condomínios fechados horizontais é desenvolvida tendo em vista as classes de maior prestígio social. Isso acontece porque ocorre a soberania no espaço urbano pelas classes dominantes, e, especialmente, pelo mercado imobiliário que escolhe e investe entre as melhores esferas do município para a implantação de empreendimentos direcionados para as classes de médio e alto poder aquisitivo (MAIA, 2017).

A nível intra-urbano, o poder público escolhe para seus investimentos em bens e serviços coletivos, exatamente os lugares da cidade onde estão os segmentos populacionais de maior poder aquisitivo; ou que poderão ser vendidos e ocupados por estes segmentos pois é preciso valorizar as áreas. Os lugares da pobreza, os mais afastados, os mais densamente ocupados vão ficando no abandono (SPOSITO, 2000, p. 91).

Sinteticamente, os moradores dos enclaves são: médicos, advogados, juízes, dentistas, militares aposentados, professores universitários, em resumo, são profissionais que ganham acima de cinco mil reais por mês, conforme explica o corretor imobiliário. Assim sendo, o morador do condomínio é homogeneizado, possuindo características sociais e econômicas semelhantes. Simultaneamente, com o espaço, é vendido um "novo" paradigma de vida urbana. Entretanto, com a implementação dos novos sistemas de segurança, criamse também espaços de segregação, entre as classes que estão dentro e as que estão fora dos enclaves.

Dessa maneira, "[...] o isolamento e homogeneidade em que a imagem confere maior status social é a da segurança, em um ambiente seguro e vigiado, entre os seus iguais" (PAULO, 2017, p. 31).

Enclaves fortificados representam uma nova alternativa para a vida urbana dessas classes médias e altas, de modo que são codificados como algo que 
confere alto status. A construção de símbolos de status é um processo que elabora distâncias sociais e cria meios para a afirmação de diferenças e desigualdades sociais (CALDEIRA, 1996, p. 308, tradução nossa).

Por fim, as camadas mais privilegiadas da sociedade têm como contingência os condomínios fechados, "[...] constituindo-se em verdadeiras ilhas no urbano, cercadas por muros altos, aparatos de segurança sofisticados e verdadeiros exércitos de agentes de segurança privada" (BOTELHO, 2007, p. 39), que dificultam a livre circulação de usuários que não fazem parte de um aparato social (camadas da população de rendimentos baixos), além da alusão de um lugar melhor, usualmente, comercializado pelas imobiliárias e seus agentes, desencadeando, assim, "[...] enclausuramento, isolamento, restrição e vigilância em símbolos de status, além do desinteresse em relacionar-se com diferentes grupos sociais, que facilmente se transforma em medo e preconceito" (LANDIM; DIGIANDOMENICO, 2014, p. 30).

\section{CONSIDERAÇÕES FINAIS}

Os novos empreendimentos imobiliários de São João del-Rei, especificamente os condomínios habitacionais fechados, no vetor norte/nordeste da cidade, seguem uma tendência disseminada em diversas cidades de porte médio do estado e do território nacional (ESTEVES; NOGUEIRA, 2013). Tais empreendimentos imobiliários têm provocado uma nova paisagem, esta segregada e fragmentada, uma vez que estão fortemente isoladas da mancha urbana. A nova paisagem acompanha a tendência de segregação socioespacial, onde encontra diretamente e profundamente com a morfologia hierarquizada socialmente, dado ao exposto que o processo de habitação é a fisionomia mais nítida das personalizações de classe. (CARLOS, 2007). Os múltiplos encontros entre o urbanismo e a fragmentação populacional da cidade, com notoriedade para o mercado imobiliário e o mercado da segurança privada, expressas pelos discursos sobre a insegurança (GOES; SPOSITO, 2014) proporcionam a busca por um habitar longe dos problemas sociais. Dessa forma, a insegurança e todas as perturbações sociais que fazem sobrevir a violência são repercussões do modelo capitalista, que intensifica e agrava as desigualdades sociais brasileiras, que se tornam mais evidentes no espaço urbano (GARROTE; MEDA, 2017).

Apesar disso, os moradores dos condomínios fechados horizontais visam, nesses modelos de habitação, a qualidade de vida, fugindo da violência urbana e buscando por segurança, ao estarem em um enclave fortificado, ladeado de elementos que asseguram a sua segurança e a segurança de seus iguais. Os altos muros instituem rupturas drásticas na paisagem urbana, que condescendem dois cenários distintos: privado e público, marcando ainda mais regimes intensos de reprodução de desigualdades (BERNARDES; SOARES 
A Expansão Urbana, o Mercado Imobiliário e a Proliferação dos Enclaves Residências Horizontais no...

JUNIOR, 2007). A segurança de bem inatingível, invariável que carecia de ser uma pretensão coletiva, transforma-se numa singularidade de mercadorias lançadas pelo marketing imobiliário na ascensão do habitar um enclave fortificado, distante do centro urbano tradicional e cercado por segurança e área verde (PEREIRA, 2005). Assim, a reprodução de espaços para habitação, ocasiona a formação dos condomínios, que pode ser compreendido tal como uma condição do aspecto de segregação espacial, salientando uma estratégia imobiliária, na qual, apresenta como alicerce a manifestação de um novo modo de vida e uma colossal qualidade de vida (CARLOS, 2007).

Simultaneamente, a classe dominante ou as frações dela, por outro lado, apartam os outros grupos sociais à medida que, o mercado de terras, as incorporações imobiliárias, e a construção são controlados, desencadeando assim, a seletividade de localização dos demais grupos sociais no espaço urbano, na qual, atuam diretamente por meio do Estado (CORRÊA, 1989).

Consequentemente, as novas formas de habitação renovam a dinâmica socioespacial e remodelam a forma tradicional de morar e, assim, vem realçando ainda mais discrepâncias entre as classes sociais (ESTEVES; NOGUEIRA, 2013).

Assim, o mercado parece desempenhar, cada vez mais, o filtro de alcance à mercadoria habitação, habituando o espaço urbano às probabilidades de rentabilidade dos agentes que o dominam, e suscitando, internamente, à cidade, níveis opostos para classes sociais distintas (BOTELHO, 2007).

Porém, sendo a cidade uma colossal concentração de sujeitos executando as mais singulares práticas, é incontestável que o solo urbano seja almejado para inumeráveis usos e funções. A discussão de solo urbano para fins de habitação também frisa vantagens habitacionais que com o tempo começam a remodelar a sua organização (SINGER, 1982). Assim, as cidades persuadem de modo direto, no que diz respeito à consolidação democrática, referente ao espaço, organização e metamorfose das relações com o "outro". Logo, o medo, pânico, o terror ao "outro" e a eclosão de condomínios fechados são fatores evidentes da restrição, no que diz respeito ao direito à cidade, que cabe ao cenário de usufruto igual do ambiente urbano (GARROTE; MEDA, 2017).

Por fim, a produção do espaço urbano provoca zonas que devido aos preços da terra são exclusivamente atribuídas e designadas às camadas sociais de maior poder aquisitivo. (KOWARICK, 2000). Em justificativa disso, permanecem particularizações entre o espaço urbano que, não só ocasionam fronteiras sociais, mas também limitam a dinâmica do direito à cidade (GARROTE; MEDA, 2017). 


\section{REFERÊNCIAS}

ANDRADE, L. T. de. Os condomínios fechados e as novas dinâmicas metropolitanas. In: ENCONTRO DE GEÓGRAFOS DA AMÉRICA LATINA, 10., 2005, São Paulo. Anais... São Paulo: UNESP, 2005. p. 837-852. 1 CD-ROM.

ANDRADE, R. B; TOLEDO, M. R; OLIVEIRA, J. S; BARBOSA, A. R. Análise crítica do atual processo de expansão urbana em São João del-Rei (MG) a partir do bairro Colônia do Marçal. In: SIMPÓSIO MINEIRO DE GEOGRAFIA, 1., 2014, Alfenas. Anais... Alfenas: UNIFAL, 2014. p. 994-1008.

\section{BARROS, I. M. B. Caracterização dos condomínios horizontais fechados de classe} média sob a ótica do transporte: um estudo de caso no Distrito Federal. Dissertação (Mestrado em Transportes) - Universidade de Brasília, 2012.

BATELLA, W. Assimetrias das relações entre verticalidades e horizontalidades no estudo de cidades médias: problematizações a partir da cidade de Teófilo Otoni - MG. GeoUECE, Fortaleza, v. 3, n. 4, p. 238-267, 2014.

BERNARDES, G. D.; SOARES JÚNIOR, A. A. Condomínios horizontais fechados: reflexão sobre a configuração do espaço intrametropolitano de Goiânia, Sociedade e Cultura, Goiânia, v. 10, n. 2, p. 209-225, 2007.

BLATT, C. R.; TOMÁS, E. D.; MACHADO, E. V. (Re) Significações de processos de urbanização, turistificação e paisagem na área central de Florianópolis (SC). In: COLOQUIO INTERNACIONAL DE GEOCRÍTICA: LA PLANIFICACIÓN TERRITORIAL Y EL URBANISMO DESDE EL DIÁLOGO Y LA PARTICIPACIÓN, 11., 2010, Buenos Aires. Anais... Buenos Aires: Universidad de Buenos Aires, 2010. Disponível em: <http://www.filo.uba.ar/contenidos/investigacion/institutos/geo/geocritica2010/345.htm>. Acesso em: 12 nov. 2018.

BOTELHO, A. A Produção do espaço urbano e da moradia através das práticas do setor imobiliário: três casos paulistanos. Cidades, Presidente Prudente, v. 4, n. 6, p. 11-43, 2007.

BRICALLI, I. L. O mito da natureza nas propagandas dos condomínios e loteamentos fechados do município da Serra/ES. Vitória: UFES/ Departamento de Geografia, 2010.

CARLOS, A. F. A. O espaço urbano: novos escritos sobre a cidade. São Paulo: USP/ FFLCH, 2007. Disponível em:

<http://gesp.fflch.usp.br/sites/gesp.fflch.usp.br/files/Espaco_urbano.pdf>. Acesso em: 14 nov. 2018.

CARNEIRO, E. J. Formações territoriais urbanas em São João del-Rei (MG). In: SIMPÓSIO NACIONAL DE HISTÓRIA, 25., 2009, Fortaleza. Anais... Fortaleza: UFC, 2009. p. 1-11.

CALDEIRA, T. P. do R. Fortified enclaves: the new urban segregation, Public Culture, Chicago, v. 8, n. 2, p. 303-328, 1996.

CALDEIRA, T. P. do R. Cidade de muros: crime, segregação e cidadania em São Paulo. São Paulo: EDUSP/Paralelo 34, 2000.

CORRÊA, R. L. O espaço urbano. São Paulo: Ática, 1989.

COTA, D. A.; DIÓRIO, A. C. D. Crescimento urbano na "pequena-média" São João Del Rei, MG: notas preliminares de uma pesquisa. In: SEMINARIO INTERNACIONAL RED IBEROAMERICANA DE INVESTIGADORES SOBRE GLOBALIZACIÓN Y TERRITÓRIO, 12., 2012, Belo Horizonte. Anais... Belo Horizonte: RII, 2012. p. 1-16. Disponível em: <https://saojoaodelreitransparente.com.br/files/docs/CRESCIMENTO_URBANO_NA_PEQU ENA-M\%C3\%89DIA_S\%C3\%830_JO\%C3\%830_DEL_REI_ _MG_NOTAS_PRELIMINARES_DE_UMA_PESQUISA.pdf>. Acesso em: 20 jan. 2018. 
A Expansão Urbana, o Mercado Imobiliário e a Proliferação dos Enclaves Residências Horizontais no...

DAL POZZO, C. F. Territórios de autossegregação e de segregação imposta: fragmentação socioespacial em Marília e São Carlos. 2011. Dissertação (Mestrado em Geografia) - Faculdade de Ciências e Tecnologia, Universidade Estadual Paulista, Presidente Prudente, 2011.

DUMONT, T. V. R. Segregação sócio espacial e a recente política urbana e habitacional nas cidades brasileiras. LEVS, Marília, n. 13, p. 129-145, 2014.

ESTEVES, M. A. V.; NOGUEIRA, M. A proliferação e a consolidação de condomínios fechados: um estudo de caso em uma cidade média - Divinópolis (MG). Geografias, Belo Horizonte, v. 9, n. 1, p. 23-39, 2013.

GARROTE, T. M.; MEDA, A. P. Medo, violência e criminalidade urbana: limitações ao exercício do direito à cidade. In: SIMPÓSIO INTERNACIONAL DE ANÁLISE CRITICA DO DIREITO, 7., 2017, Jacarezinho. Anais... Jacarezinho: UENP, 2017. p. 189-2010. Disponível em: <http://siacrid.com.br/repositorio/2017/violencia-e-criminologia.pdf\#page=189>. Acesso em: 12 nov. 2018.

GOES, E. M.; SPOSITO, M. E. B. A insegurança e as novas práticas espaciais em cidades brasileiras. In: COLOQUIO INTERNACIONAL DE GEOCRÍTICA EL CONTROL DEL ESPACIO Y LOS ESPACIOS DE CONTROL, 13., 2014, Barcelona. Anais... Barcelona: Universitat de Barcelona, 2014. p. 1-12. Disponível em: <http://www.ub.edu/geocrit/coloquio2014/Eda\%20Maria\%20Goes.pdf>. Acesso em: 7 fev. 2018.

GOMES, L. C.; AGUIAR, L. M. B. de. Notas sobre a formação territorial do município de São João del-Rei e o reordenamento espacial a partir do processo de modernização agrícola.

Territorium Terram, São João del-Rei, v. 1, n. 2, p. 37-51, 2012.

IBGE. Cidades. Disponível em: <https://cidades.ibge.gov.br/brasil/mg/sao-joao-delrei/panorama>. Acesso em: 17 jan. 2018.

JORDÃO, L. C. S. Novas periferias urbanas: a expansão de São Carlos através de condomínios fechados. 2010. Disponível em:

<http://www.historia.uff.br/estadoepoder/7snep/docs/020.pdf>. Acesso em: 8 jan. 2018.

MOREIRA JÚNIOR, O. Cidade partida: segregação induzida e auto segregação urbana. Caminhos de Geografia, Uberlândia, v. 11, n. 33, p. 1-10, 2010.

$\mathrm{KOCH}, \mathrm{M}$. R. Condomínios fechados: as novas configurações do urbano e a dinâmica imobiliária. Indicadores Econômicos, Porto Alegre, v. 35, n. 3, p. 99-116, 2008.

KOWARICK, L. Escritos urbanos. São Paulo: Ed. 34, 2000.

LANDIM, G. R.; DIGIANDOMENICO, D. Organicidade parâmetros para um mais vivo. Trabalho de Conclusão de Curso. 2014. (Graduação em Arquitetura e Urbanismo) - Centro Universitário Belas Artes de São Paulo, São Paulo, 2014.

MAIA, L.M.de. Habitação de interesse social e a produção do espaço urbano em São João del-Rei/MG entre os anos 2006-2016. 2017. Dissertação (Mestrado em Geografia) Universidade Federal de São João Del-Rei, São João Del Rei, 2017.

MALDOS, R. A formação urbana da cidade de São João del-Rei. 2000. Disponível em: <http://www.saojoaodelreitransparente.com.br/works/view/605>. Acesso em: 8 jan. 2018.

MARINHO, M. J. Cidade cercada: um modelo irreversível de expansão urbana? In: SEMINARIO INTERNACIONAL DE INVESTIGACIÓN EN URBANISMO: CIUDAD, TERRITORIO Y PAISAJE, 9., 2017, Barcelona. Anais... Barcelona: Universitat Politècnica de Catalunya, 2017. p.13-23.

MARTINS, M. Condomínios habitacionais fechados e qualidade de vida: uma discussão sobre a cidade. In: CONGRESSO PORTUGUÊS DE SOCIOLOGIA: MUNDOS SOCIAIS: 
SABERES E PRÁTICAS, 6., 2008, Lisboa. Anais... Lisboa: Universidade Nova de Lisboa, 2008. p. 1-21.

MARTINS, M. Condomínios habitacionais fechados e qualidade de vida: uma discussão sobre a Cidade. IN: CONGRESSO PORTUGUÊS DE SOCIOLOGIA: MUNDOS SOCIAIS: SABERES E PRÁTICAS, 6., 2008, Lisboa. Anais... Lisboa: Universidade Nova de Lisboa. Lisboa, 2008. p. 1-21.

MOTTER, C.; BATELLA, W. C. Descentralização e novas centralidades em cidades médias: o caso do subcentro da avenida São Pedro em Chapecó. Boletim Gaúcho de Geografia, Porto Alegre, v. 42, n. 2, p. 611-627, 2015.

OLIVEIRA, J. T; TOLEDO, M. R. A valorização imobiliária em São João Del-Rei: transformações urbanas. In: ENCONTRO NACIONAL DE GEÓGRAFOS: A CONSTRUÇÃO DO BRASIL: GEOGRAFIA, AÇÃO POLÍTICA E DEMOCRACIA, 18., 2016, São Luís.

Anais... São Luís: UFMA, 2016. p. 1-10.

PAULO, F. G. Muros e Condomínios fechados: reestruturação da cidade do Rio de Janeiro. Revista Tocantinense de Geografia, Araguaína, v. 6, n. 9, p. 22-35, 2017.

PEREIRA, P. C. X. Reestruturação imobiliária em São Paulo: especificidades e tendências. In: ENCONTRO DE GEÓGRAFOS DA AMÉRICA LATINA, 10., 2005, São Paulo. Anais... São Paulo: UNESP, 2005. p. 11626-11638.

SILVA, A. L. A. Minha casa ... E a vida? impactos socioespaciais a partir da análise de um empreendimento do programa minha casa, minha vida em São João del Rei, MG.

Dissertação (Mestrado em Geografia) - Universidade Federal de São João del-Rei, 2018.

SILVA, K. O. Condomínios fechados, residências secundárias e o uso do espaço público pelo capital imobiliário. Revista Acadêmica Observatório de Inovação do Turismo, Rio de Janeiro, v. 4, n. 1, p. 1-15, 2009.

SINGER, P. O uso do solo urbano na economia capitalista. In: MARICATO, E. (Org.). A produção capitalista da casa (e da cidade) no Brasil Industrial. São Paulo: Alfa Omega, 1982. p. 21-37.

SPOSITO, M. E. B. Capitalismo e urbanização. São Paulo: Contexto, 2000.

TEIXEIRA, M. E. Ser italiano em São João del Rei (1888-1914). 2011. Tese (Mestrado em História) - Universidade Federal de Juiz de Fora, Juiz de Fora, 2011.

UEDA, V. Os novos empreendimentos imobiliários e as transformações recentes no espaço urbano de Porto Alegre. In: ENCONTRO DE GEÓGRAFOS DA AMÉRICA LATINA, 10., São Paulo. Anais... São Paulo: UNESP, 2005. p. 15948-15965. Disponível em:

<https://docplayer.com.br/6197864-Os-novos-empreendimentos-imobiliarios-e-astransformacoes-recentes-no-espaco-urbano-de-porto-alegre-1.html>. Acesso em: 12 nov. 2018.

ZANDONADI, J. C. A legalidade e (i)legalidade na implantação de loteamentos fechados e condomínios horizontais: uma análise da produção do espaço em uma cidade média Marília - SP - Brasil. In: ENCONTRO DE GEOGRAFIA DA AMÉRICA LATINA, 10., 2005, São Paulo. Anais... São Paulo: USP, 2005. p. 16649-16661. Disponível em: <http://observatoriogeograficoamericalatina.org.mx/egal10/Geografiasocioeconomica/Orden amientoterritorial/66.pdf>. Acesso em: 5 fev. 2018.

Recebido: agosto de 2018. Aceito: novembro de 2018. 